\title{
Role of seasonality and rainfall in Vibrio cholerae infections: A time series model for 11 years surveillance data
}

\author{
Tunny Sebastian $^{a}$, Shalini Anandan ${ }^{b}$, Visalakshi Jeyaseelan ${ }^{a}$, \\ Lakshmanan Jeyaseelan $^{a, *}$, Kavitha Ramanathan ${ }^{a}$, \\ Balaji Veeraraghavan ${ }^{b}$ \\ ${ }^{a}$ Department of Biostatistics, Christian Medical College, Vellore, India \\ ${ }^{\mathrm{b}}$ Department of Microbiology, Christian Medical College, Vellore, India
}

\section{A R T I C L E I N F O}

Article history:

Received 30 December 2014

Accepted 1 May 2015

Available online 23 May 2015

Keywords:

Vibrio cholerae

Rainfall

Time series

Seasonality

Harmonic regression

\begin{abstract}
A B S T R A C T
Background: Cholera is a life threatening disease, which alone contributes to the mortality of 2.2 million people globally, per year. The aim of this article was to study the trend, seasonality and the association of Vibrio cholerae(V. cholerae) cases with environmental factors such as Rainfall, Temperature and Humidity over 11 years.

Methods: Data on V. cholerae were extracted from laboratory records of Department of Clinical Microbiology, Christian Medical College, Vellore (India) between 2000 and 2010. Time series models such as Auto regressive model, Seasonal auto regressive integrated moving average model, Segmented regression model and Harmonic regression model with sine and cosine functions were done to analyze the data.

Results: There were 132 months of observations and 1039 cholera cases reported during this time. The total number of Vibrio cholerae 01 and 0139 reported was 940 and 99 cases, respectively. The number of cases reported gradually declined after 2004. The overall mean (sd) of monthly cholera counts was 7.9 (8.2). Results suggested that there was a near significant reduction of 50\% from 2000-2004 to 2005-2010 with mean (sd) were 11.2(8.0) and 5.1(7.4) respectively. The average peak time during the first time period was August, while July was during the second time period. During 2000-2004, there was a positive significant association between Rainfall and V. cholerae cases $(r=0.51, p<0.001)$ and this was not observed in the second time period.

Conclusion: The trend of V.cholerae was decreasing from 2000 to 2010 and there was a significant association between Rainfall and cholera cases between 2000 and 2004.
\end{abstract}

(C) 2015 INDIACLEN. Published by Elsevier B.V. All rights reserved.

\footnotetext{
* Corresponding author at: Department of Biostatistics, Christian Medical College Vellore 632002, India.

Tel.: +91 (0) $4162262703,+91$ (0) 4162284205.

E-mail address: ljey@cmcvellore.ac.in (L. Jeyaseelan).

http://dx.doi.org/10.1016/j.cegh.2015.05.001

2213-3984/C 2015 INDIACLEN. Published by Elsevier B.V. All rights reserved.
} 


\section{Introduction}

Cholera is a life threatening disease, which alone contributes to the mortality of 2.2 million people globally per year. ${ }^{1,2}$ Cholera is an acute diarrheal disease caused by the bacterium Vibrio cholerae (V. cholerae) of serogroups $\mathrm{O} 1$ and $0139 .^{3}$ Death occurs due to severe dehydration and electrolyte imbalance. There are many cases of acute watery diarrhea reported in Asia, but the proportion due to $V$. cholerae is unknown and many cases are not recorded due to limitations in the surveillance systems. The main reasons for cholera outbreaks in rural areas are primarily, lack of safe drinking water and improper sanitation.

Infectious disease transmission should be viewed with certain ecological factors which vary from region to region. Cholera transmission is mainly related to environmental factors which are directly related to climatic variability. In Asia, cholera rates are much higher during monsoon periods. ${ }^{4}$ Several scientific studies have also demonstrated the involvement of climatic factors in the recurrence of epidemic cholera. ${ }^{5-8}$ Rogers $(1926,1930)$ reported that V.cholerae infection was higher in April and May but had been shifted recently to September and October with two peaks annually., ${ }^{9,10}$ Emergence of several viral diarrhoea infections due to climate variability in Bangladesh, Thailand, Australia and China have been reported but very few studies have looked at seasonal variability in cholera using time series models. ${ }^{2,5,8,11}$ The aim of this paper was to study the trend, seasonality of cholera cases reported in a referral hospital over a period of 11 years and study the association between environmental variables and V.cholerae cases.

\section{Methods}

\subsection{Data source}

\subsubsection{Cholera data}

The Department of Clinical Microbiology receives stool samples that are sent for culture of common enteric pathogens. Stool samples of patients coming to the Emergency department or admitted with a history of passing watery and frequent stools were registered for a culture with hanging drop which were then processed for V.cholerae. This data was extracted from laboratory records between January 2000 and December 2010.

\subsubsection{Environmental factors}

The local climatic variables that were included in this study such as monthly mean maximum temperature (degree Celsius), monthly total rainfall ( $\mathrm{mm}$ ) and relative humidity at $1730 \mathrm{~h}$ IST (\%) were obtained from the records of Regional Meteorological Department, Chennai for the period of January 2000-December 2010. Private drinking water-supply information of Vellore City was also collected from suppliers. The year of establishment and their daily production in Liter were collected.

\subsection{Statistical methods}

The analyses considered V.cholerae $\mathrm{O} 1$ and V.cholerae 0139 as V.cholerae or cholera counts. Seasonal auto regressive integrated moving average (SARIMA) models were fitted in order to control for seasonal effect on the cases. ${ }^{12,13}$ In addition, it was assumed that there was an autocorrelation amongst the numbers reported between months. As the numbers of cases reported started declining from 2005 onwards, the analyses were done for two strata of time periods, that is, 2000-2004 and 2005-2010. The simple auto regressive (AR) model was performed for the second period observations. However, this was validated using segmented time series analyses. Using this method we also estimated the average difference between the two time periods and the rate of change after the segment period. Auto correlation function (ACF) and partial auto correlation function (PACF) graphs were plotted against time to find the parameters for SARIMA model. ${ }^{2,12}$

Poisson harmonic regression (PHR) model with sine and cosine function was used to find the average peak time at which the maximum number of V.cholerae cases were reported. ${ }^{2,14,15}$

\section{Results}

The Vellore district population in 2011 was 3,936,331 of which male and female were 1,961,688 and 1,974,643 respectively. In 2001 census, Vellore had a population of 3,477,317 of which males were 1,741,083 and remaining 1,736,234 were females. Thus there was an increase of $13.2 \%$ in 2011 population compared to population in $2001 .{ }^{16}$ Vellore had been generally having warm weather with a mean (sd) rainfall of 117.2(63.2) $\mathrm{mm}$ and the number of rainy days was 67 (2.5 $\mathrm{mm}$ and above) in 2010. The rainfall was maximum during September and October. In 2010, the mean (sd) temperature and humidity was 33.9(4.0) ${ }^{\circ} \mathrm{C}$ and $59.3(14.9) \%$ respectively and the temperature was maximum during May.

There were 132 months observations from the year 2000 to 2010 on V. cholerae. The mean cholera count was 7.9 with sd 8.2. V. cholerae 0139 was found to be present till 2003 and the maximum count was 13 , whereas the maximum count for $\mathrm{O} 1$ type was 27 , except the count in June 2008, which was 49 . This high count was replaced with monthly average in June, which was 8, for the purpose of modelling. The mean (sd) of V. cholerae $\mathrm{O} 1$ and 0139 reported during this period was 7.1(7.4) and 0.8 (2.0) cases per month respectively. Of the total subjects studied, $40 \%, 24 \%, 29 \%$ and $7 \%$ were in the age groups (in years) of $<15,15-34,35-59$ and 60 and over, respectively. Among the total around $26 \%$ of the subjects were children with age less than 5 years. Most of the patients were males (58\%), while females were $42 \%$.

The trend of V.cholerae by year and months of reporting during the study period is presented in Fig. 1. The number of cases reported gradually declined after 2005, and then increased in 2010. That is, the mean (sd) of cases reported from 2000 to 2004 and 2005 to 2010 was $11.2(8.0)$ and 5.1(7.4) respectively.

The results suggested that there was a significant reduction between the two time periods (2000-2004 Vs 2005-2010), that was $-5.4(p<0.001)$. On an average there were about 5 cases reported less during the second period as compared to the first period. The rate of change during the second period was nearly 2.7 cases per year, which was statistically significant. 


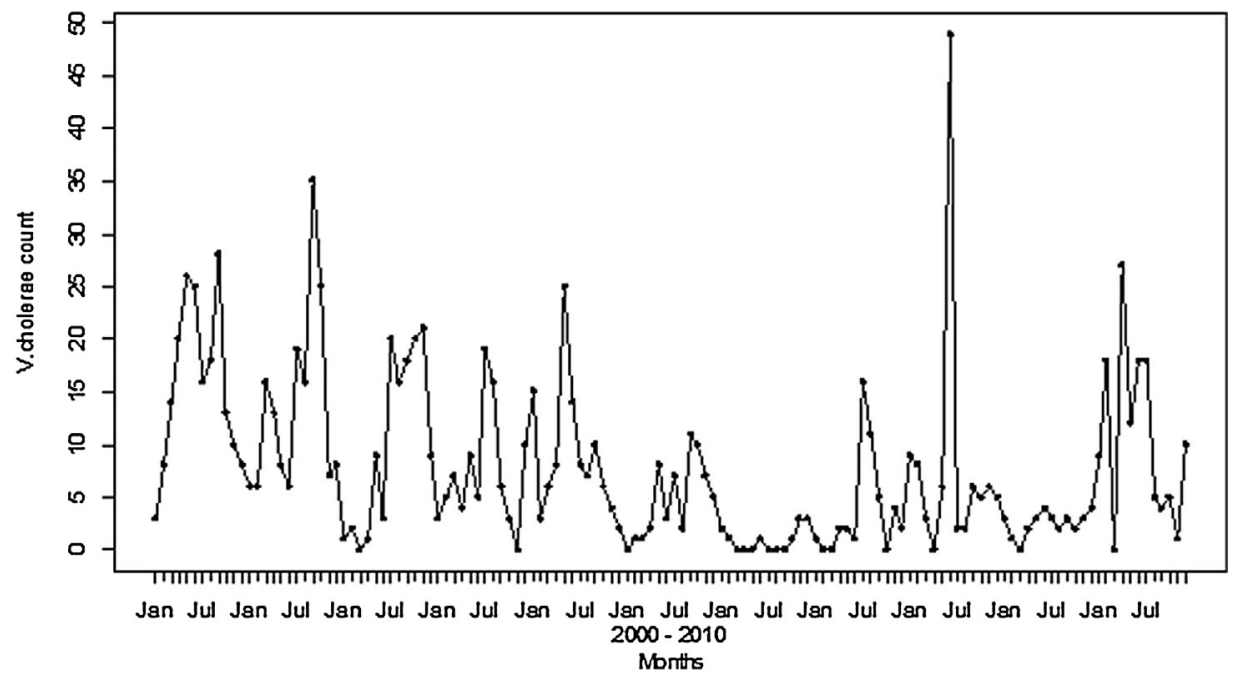

Fig. 1 - Time Series plot of monthly Vibrio cholerae for 11 years.

The average peak time, at which the maximum number of cases was reported during the time period 2000 - 2004 was at the 7.6th month, indicating that more number of cases were reported around August. The maximum number of cases reported was 17 and minimum number of cases reported was 6. However, in the second time period (2005-2010), this was the 6.95 th month, indicating that in the month of July more number of cases were reported. The maximum number of cases reported was 6 and minimum number of cases reported was 3.

The mean (sd) rainfall during the rainy season (August to November) was 161(89) $\mathrm{mm}$. Overall, there was a negative correlation between rainfall and the V.cholerae cases reported. However, there was a positive correlation between rainfall and V.cholerae cases until 2004 in the bivariate analyses $(r=0.51$,

Table 1 - Regression model coefficients for environmental variables.

\begin{tabular}{lccr} 
Parameter & Estimate & SE & P value \\
\hline Period:2000-2010 Model: SARIMA $(1,0,0)$ & $(0,1,1)_{12}$ & \\
AR 1 & 0.491 & 0.082 & $<0.001$ \\
SMA 1 & 0.802 & 0.158 & $<0.001$ \\
Rainfall & -0.009 & 0.005 & 0.044 \\
Temperature & -0.044 & 0.040 & 0.281 \\
Humidity & 0.024 & 0.026 & 0.344 \\
Period: 2000-2004 Model: SARIMA $(1,0,0)(1,0,0)_{12}$ & \\
AR 1 & 0.492 & 0.121 & $<0.001$ \\
SAR 1 & 0.173 & 0.144 & 0.234 \\
Rainfall & 0.040 & 0.009 & $<0.001$ \\
Temperature & 0.469 & 0.139 & 0.001 \\
Humidity & -0.139 & 0.084 & 0.104 \\
Period: 2005-2010 Model: AR(2) & & \\
AR 1 & 0.213 & 0.117 & 0.073 \\
AR 2 & 0.348 & 0.117 & 0.004 \\
Rainfall & 0.007 & 0.007 & 0.327 \\
Temperature & 0.105 & 0.079 & 0.188 \\
Humidity & 0.003 & 0.050 & 0.958 \\
\hline
\end{tabular}

$p<0.001$ ). From 2005 onwards there was no significant correlation observed between total rainfall and V.cholerae cases. There was no significant correlation between mean maximum temperature and the V.cholerae cases and similarly the mean relative humidity and V.cholerae cases.

The results of time series regression models are presented in Table 1. For the overall period, the significant peak of ACF at 12 suggested the presence of an annual seasonal component in the data ( $p<0.001$ ). Thus, the maximum number of cases was reported in August. Rainfall was negatively associated with V. cholerae, which was statistically significant $(p<0.04)$. During the period 2000-2004, the rainfall and temperature were significantly associated with V.cholerae $(\mathrm{p}<0.001)$. However, during the period 2005-2010, there was no such relationship.

\section{Discussion}

The Christian Medical College and Hospital (CMCH) is a referral hospital with a well established referral microbiology laboratory. There is a good system of documentation of all laboratory records in the Department of Microbiology. Our study has shown that there is a seasonality in V.cholerae and also that there is a significant association between rainfall and $V$. cholerae over these years. However, this association was not significant in the later part of the study period, that is, from 2005 to 2010. This may be due to the power of the study, insufficient time period, due to changes in the drainage system, availability of good quality drinking water by the government or due to the evolution of the bottled water industry since 2004.

Our survey on bottled water companies revealed that there were 10 companies producing 166,000 litters of water prior to year 2004, while this was 532,000 litters from 2004 to 2010. There were 20 new companies established from 2004 to 2010. The mean consumption of good quality water consumed by an individual prior to 2004 was 0.39 litters, while this was 1.05 litters from 2004 to 2010. Thus, there was a three times 
increase in good quality water production and consumption in the latter period (2004-2010) which maybe strongly associated with the decline in the incidence of cholera during the second period.

Faruque et al. (2005) and Islam et al. (2004) have reported that cholera epidemics are usually attributed to a single bacterial clone and the outbreak begins from a point source and then spreads. ${ }^{17,18}$ Several studies have shown cholera epidemics are associated with environmental factors. ${ }^{5-7,9,19-25}$ However, they have also raised concerns as to what point source cholera spreads from and where the first clone of an epidemic appears. In our study there has been a significant reduction in the number of cases reported during the period 2005-2010. This could be attributed to availability and affordability of good quality of drinking water and also due to improved sewage drainage system established in recent years. Therefore, it is presumed that these changes would have cleared the reservoir of the V.cholerae $\mathrm{O} 1$ and 0139 types in the city.

Sack et al. (2006) have reported seasonality of V.cholerae. ${ }^{26}$ The seasonality was observed during spring peak (during monsoon) and also in the fall peak (after monsoon). They have also reported that the study area Bakerganj can be considered to be an area where V.cholerae $\mathrm{O} 139$ is endemic. In our study also we observed seasonality during the months of June and July, whenever we have the south west monsoon. Usually during this period the rainfall is scanty, however higher number of cases were reported. But cases of V.cholerae $\mathrm{O} 1$ were reported less during the main monsoon period in the state of Tamil Nadu which falls during the months of November and December. Our data showed that whenever there was a spell of rain then the reporting of cholera cases was less. Similar findings have been reported in other studies. ${ }^{27}$

The association between rainfall and humidity and the increase in V.cholerae counts have been shown to be significant by many authors (Rajendran et al., 2011; Lipp et al., 2002; Pascual et al., 2002; Ruiz-Moreno et al., 2007).,28-30 Moreover, unlike Bangladesh, Vellore is situated away from the coastal area and therefore the association between V.cholerae and planktonic copepods is ruled out.

The findings of this study are based on hospital surveillance data, consequently there is likely to be under reporting, as a good number of cases of cholera may have been treated by private practitioners. However, there are 7 other hospitals that are catering to the need of the local population in Vellore taluk. As these hospitals have diagnostic facility and are able to treat, may be that the numbers would have come down. However, only two hospitals were established after 2004. Therefore, more infrastructure facilities would not have contributed very much to the reduction in the number of cases. Moreover, the $\mathrm{CMCH}$ laboratory has not changed any practices and clinicians still send samples to the laboratory as they had been doing in the past for all watery and loose stool samples even after working hours as emergency samples. Smaller hospitals or clinics generally do not confirm cholera cases based on laboratory confirmation but presumption from a clinical picture. Some hospitals can do just a "hanging drop" and base their diagnosis on this. There are very few labs that have culture and antiserum facilities available.
Thus the 15 years data on V.cholerae would be able to provide a comprehensive knowledge about the epidemiology of V.cholerae in and around Vellore District.

\section{Ethical clearance}

This study was approved by the Institutional Review Board of Christian Medical College Vellore; IRB.Min.No.7109 dated 10.03.2010.

\section{Conflicts of interest}

All authors have none to declare.

\section{Acknowledgment}

We gratefully acknowledge the funding support of CMC Fluid Research grant.

\section{REFERENCES}

1. WHO | The global burden of disease: 2004 update [Internet] WHO. [cited 2014 Jan 17]. Available from: http://www.who. int/healthinfo/global_burden_disease/2004_report_update/ en/index.html.

2. Rajendran K, Sumi A, Bhattachariya MK, et al. Influence of relative humidity in Vibrio cholerae infection: a time series model. Indian J Med Res. 2011;133:138-145.

3. Harris JB, LaRocque RC, Qadri F, Ryan ET, Calderwood SB. Cholera. Lancet. 2012;379:2466-2476.

4. Sack DA, Sack RB, Nair GB, Siddique AK. Cholera. Lancet. 2004;363:223-233.

5. Magny e, Murtugudde R, Sapiano MRP, et al. Environmental signatures associated with cholera epidemics. Proc Natl Acad Sci. 2008;105:17676-17681.

6. Huq A, Sack RB, Nizam A, et al. Critical factors influencing the occurrence of Vibrio cholerae in the environment of Bangladesh. Appl Environ Microbiol. 2005;71:4645-4654.

7. Colwell RR. Global climate and infectious disease: the cholera paradigm. Science. 1996 Dec 20;274:2025-2031.

8. Fernández M\&a, Bauernfeind A, Jiménez JD, Gil CL, Omeiri $\mathrm{NE}$, Guibert DH. Influence of temperature and rainfall on the evolution of cholera epidemics in Lusaka, Zambia, 2003-2006: analysis of a time series. Trans R Soc Trop Med Hyg. 2009;103:137-143.

9. Rogers L. The conditions influencing the incidence and spread of cholera in India. Proc R Soc Med. 1926; 19:59-93.

10. Rogers L. Further experience in forecasting epidemics of Smallpox, Plague, and Cholera in India, and its bearing on the reduction of cholera. Proc R Soc Med. 1930;23:793-802.

11. Hashizume M, Wagatsuma Y, Faruque ASG, et al. Factors determining vulnerability to diarrhoea during and after severe floods in Bangladesh. J Water Health. 2008;6:323.

12. Hu W, Tong S, Mengersen K, Connell D. Weather variability and the incidence of cryptosporidiosis: comparison of time series poisson regression and SARIMA models. Ann Epidemiol. 2007;17:679-688.

13. Cooray TMJ. Applied Time Series: Analysis and Forecasting. Oxford: Alpha Science International Ltd; 2008. 
14. Stolwijk AM, Straatman H, Zielhuis GA. Studying seasonality by using sine and cosine functions in regression analysis. $J$ Epidemiol Community Health. 1999;53:235-238.

15. Kinlin LM, Spain CV, Ng V, Johnson CC, White ANJ, Fisman DN. Environmental exposures and invasive meningococcal disease: an evaluation of effects on varying time scales. Am J Epidemiol. 2009;169:588-595.

16. Vellore District: Census 2011 data. Available from: http:// www.census2011.co.in/census/district/23-vellore.html.

17. Faruque SM, Islam MJ, Ahmad QS, et al. Self-limiting nature of seasonal cholera epidemics: role of host-mediated amplification of phage. Proc Natl Acad Sci U S A. 2005;102:6119-6124.

18. Islam MS, Talukder KA, Khan NH, et al. Variation of toxigenic Vibrio cholerae $\mathrm{O} 1$ in the aquatic environment of Bangladesh and its correlation with the clinical strains. Microbiol Immunol. 2004;48:773-777.

19. Constantin de Magny G, Murtugudde R, Sapiano MRP, et al. Environmental signatures associated with cholera epidemics. Proc Natl Acad Sci U S A. 2008;105:1767617681.

20. Jutla A, Whitcombe E, Hasan N, et al. Environmental factors influencing epidemic cholera. Am J Trop Med Hyg. 2013;89:597-607.

21. Koelle K. The impact of climate on the disease dynamics of cholera. Clin Microbiol Infect Off Publ Eur Soc Clin Microbiol Infect Dis. 2009;15:29-31.
22. Longini Jr IM, Yunus M, Zaman K, Siddique AK, Sack RB, Nizam A. Epidemic and endemic cholera trends over a 33-year period in Bangladesh. J Infect Dis. 2002;186:246-251.

23. Mishra A, Taneja N, Sharma M. Environmental and epidemiological surveillance of Vibrio cholerae in a choleraendemic region in India with freshwater environs. J Appl Microbiol. 2012;112:225-237.

24. Glass RI, Becker S, Huq MI, et al. Endemic cholera in rural Bangladesh, 1966-1980. Am J Epidemiol. 1982;116:959-970.

25. Gupta N, Dewan S, Saini S. Resurgence of Vibrio cholerae O139 in Rohtak. Indian J Med Res. 2005;121:128-130.

26. Sack RB, Siddique AK, Longini Jr IM et al. A 4-year study of the epidemiology of Vibrio cholerae in four rural areas of Bangladesh. J Infect Dis. 2003;187:96-101.

27. Alam M, Hasan NA, Sadique A, et al. Seasonal cholera caused by Vibrio cholerae serogroups $\mathrm{O} 1$ and 0139 in the coastal aquatic environment of Bangladesh. Appl Environ Microbiol. 2006;72:4096-4104.

28. Lipp EK, Huq A, Colwell RR. Effects of global climate on infectious disease: the cholera model. Clin Microbiol Rev. 2002;15:757-770.

29. Pascual M, Bouma MJ, Dobson AP. Cholera and climate: revisiting the quantitative evidence. Microbes Infect. 2002;4:237-245

30. Ruiz-Moreno D, Pascual M, Bouma M, Dobson A, Cash B Cholera seasonality in Madras (1901-1940): dual role for rainfall in endemic and epidemic regions. EcoHealth. 2007;4:52-62. 